\title{
REGIONAL SUSTAINABLE DEVELOPMENT THROUGH ENHANCING THE REGIONAL GRADUATES EMPLOYABILITY; CASE OF GEORGIA
}

(iD) Natela Tsiklashvili ${ }^{1}$, Doctor of Economics/ Professor; iamari Poladashvili², PhD student of Business Administration /Invited Lecturer

\author{
1,2 Batumi Shota Rustaveli State University
}

\begin{abstract}
Education, in general, creates strong basics of sustainable development. Higher education is one of the important settings for accomplishing better education and quality of human life. Region based higher educational institutions (HEIs) have high input in regional economic development through traditional functions of teaching and research. Educational institutions acquiring graduates with relevant knowledge and skills for the labour market. The given paper examines: How Georgian regional universities enhance the graduates' employability and workforce formation? Do the institutions encouraging university-business interactions? What are the main challenges and optimal ways of improvement? The article is using a qualitative research method with a combination of mixed research techniques by collecting and analysing other qualitative and quantitative information from national governmental reports, scientific articles, and annual statistical data.

The paper draws the background information, that enhances the bed climate for recent graduates on the labour market, the unemployment and employment rate, proportion of horizontal mismatch, fields or groups of studies that students are most likely to be mismatched, its cause and effects relationship.

Results show that institutions have week interaction with regional enterprises and SMEs: HEIs do not have skills anticipation strategy based on the regional business sector to avoid potential misbalance in the labour market. HEIs instead of showing initiative often take a proactive position and are looking at interactions between labour market stakeholders; they have weak interaction with public and private enterprises. Regional SMEs' participation in creating curriculums is uncommon.
\end{abstract}

Key words: regional sustainable development; higher education; labour force; employment; Georgia.

JEL: R23; J21; I23

\section{Introduction}

Scholars and academics have broadly discussed the sustainable development concept. The United Nations Decade of Education for Sustainable development (2005-2014) mobilizes educational resources for a sustainable prospect. According to UNESCO "education alone cannot achieve a more sustainable future; however, without education and learning for sustainable development, we will not be able to reach other sustainable goals" (2005).

Higher education keeps the central position for sustainable development, as it is one of the main pillars of delivering advanced knowledge, skills, and appropriate values for the local community, to address the suitable behaviour, which is necessary for sustainable development. HEIs have the primary goal of acquiring graduates with new knowledge, prepare leaders, managers, teachers, and other professionals for the future. Sufficient education will help them to take action considering sustainable development goals. Therefore, the quality of education and well-planned education-job transition process creates good bases for employment and enhances the better quality of life.

In Georgia, graduates' employability issues and occupation by profession are getting more and more attention. Questions raise on addressing Authorities and Higher educational institutions. There is a debate, discussion, and arguments among politicians, education authorities, labour market stakeholders, and experts regarding the qualifications and skills of recently graduated students. Since 2005, the Bologna Process has been announced and a three-cycle HE system has been implemented. In the last 20 years, the higher education sector created a high number of graduates in a variety of disciplines. However, individuals 
experience difficulties in finding appropriate jobs. Numbers of graduates are occupying positions that do not apply to their background education, experience, and expectation.

With the radical changes in the sector and expansion of higher educational institutions, today, Georgia experiences a greater imbalance between higher education graduates and labour market demands. The main concerns arise regarding graduates' unemployment, hard transitions from education to occupation, mismatch with the profession, and securing the job for lifelong. The process is even longer for women compared to men. As women take more responsibilities for family duties and enter at labour market later rather than men.

After graduating from HEIs individuals often face two main obstacles: Professions they have obtained are not in demand in the labour market and/or their skills and qualifications do not meet the labour market requirements.

\section{Conceptual framework}

The role of the higher educational institutions in preparing graduates for the labour market is a long-lasting and debating subject (Barnett, 2000). Several studies argue that entrant students, their families, and employers have the expectations that simply graduating from university will acquire them with all necessary labour required skills (Crebert, Bates, Bell, Patrick, \& Cragnolini, 2004; Bannett, Dunne, \& Carre, 2002; Atkins, 1999). Perceptions and responses regarding the needs and expectations of employers differ across universities. However, two individuals graduating from the same major field will not essentially find the same job opportunities, hence, returns from education may also diverse (Carnevale \& Cheah, 2013a; Carnevale at al., 2013b). Therefore, fresh graduates leading complicated decision-making processes, that are influenced by market conditions, labour demand, employable skills, abilities, and their perspectives in this regard (Hwang, 2017). At this time, when a mismatch between the major field of education and the main skills required for job unsuits, is stated as a horizontal mismatch. According to Robst (2006), a horizontal mismatch is referred to as job-education mismatch or education-occupation mismatch. Labour market imbalance by nature is usually connected with the differentiation among labour supply and demand, "skills mismatch can occur when total supply meets total demand with numbers, however not with skills or/and qualification" (Badurashvili, 2019). Horizontal mismatch approaches the relationship between graduates' specific field of study and knowledge and labour market demand in the context of human capital, transferable and professional skills (Robst, 2007; Beduwe \& Giret, 2010). According to Rudakov et al., 2019, labour market develops more frequently rather than the educational system, therefore the educational system cannot react immediately to certain professions. Mismatch on the labour market might link the risk of unemployment, job dissatisfaction, bed quality life, etc. (Bender $\&$ Roche, 2013; Boudarbat \& Chernoff, 2012; Cosser, 2010). On the other hand, the mass labour market cannot create a sufficient amount of job places, while HEIs provide an oversupply of graduate students for some particular fields. Negative consequences of horizontal mismatch have been studied by a number of authors Nordin, Persson, \& Rooth, 2010; Robst, 2007 etc.

\section{Research method}

The purpose of the given work is to investigate the main challenges that exist between Higher education graduates and labour market stakeholders. Particularly, the authors examined: 1) how regional-based HEIs enhance the fresh graduates' employability, and how it helps regional sustainability; 2) what are the factors of unemployment and reasons for a horizontal mismatch; 3) what are the main challenges and optimal ways of improvement. 
Qualitative research has been done among all Georgian higher educational institutions and teaching institutes located at the regional based in Georgia. Two educational institutions refuse to participate in the research due to internal politics. As a result, 10 institutions have been involved in the study. Participants of the in-depth interview from each university were vice-rectors or head of the quality assurance services or head of the career centres and other competent persons depending on the structure of the HEIs. The total majority of HEIs participating in the study have undergone authorization and program accreditation, as they have the right to implement BA, MA, Ph.D. programs, according to the type of institution.

To address the research problem, we chose the mixed research method, as one of the complex research techniques. We used secondary data analysis that had been collected previously and tabulated by other sources. The data were reliable and professionally gathered. Practically it is the utilization of existing records (Johnston, 2014; Bhattacherjee, 2012; Andrews, Higgins, Andrews, \& Lalor, 2012). Also, methods of analysis and synthesis were used to formulate conclusions and final recommendations.

\section{Research Results and Discussion}

\section{- A general overview of youth unemployment in Georgia}

Research participants' approach that general unemployment in the country have high impact on regional unemployment trend. The labour market in Georgian had trouble alongside governmental and economic changes. Unemployment rates are permanently high with the young generation. It reached the highest peak in 2009 that ware caused by the August conflict between Russia and Georgian, which were ongoing at the same time as the world financial crises. Since 2010, the trend keeps declining. According to the National Statistical Office, the overall unemployment rate with the population above $15+$ age for 2020 is $18.5 \%$.

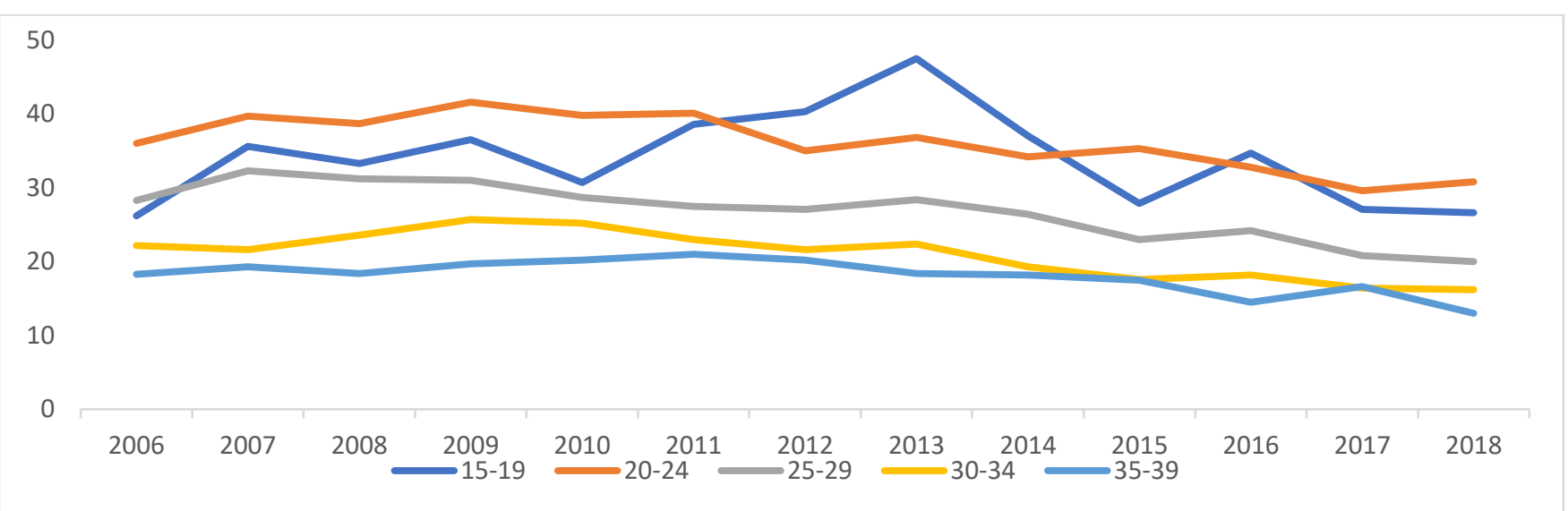

\section{Source: author's calculations based on National Statistics Office of Georgia, 2020}

Fig. 1. Distribution of Unemployment rate (percentage) by age groups 2006-2018

Individuals aged 15-19 are usually at school or in the first year of vocational/tertiary education and they usually do not work, as families support them. More than $80 \%$ of the total population with the age of 20-24 are at the vocational/tertiary education or graduated Bachelor Degree. Therefore, the individuals are skilled enough to get into the labour market; however, the number of unemployment is at a pick with this age group rather, than any other cluster. Meaning that fresh graduates experience a very low rate of employment (Fig. 1). The unemployment trend significantly decreases for the people the age of 25-29, as it is mostly because of several reasons:

a) At this age, most of the individuals are Master graduate, which increase the chances of employment.

b) Individuals have to take any offered job to maintain themselves. 
Overall, the labour force unemployment rate is rather high, which influences fresh graduates' employability possibilities and decreases chances for individuals to recruit (Fig. 1).

- How the HEIs' market condition influence graduates' unemployment?

Georgia traditional had very high-level participation in higher education that ware caused mainly by family traditions and educational approaches from the post-Soviet era. With a gross tertiary enrolment ratio of $30 \%$, country ware ranked as one of the highest participation rates among the Soviet countries (Chakhaia \& Bregvadze, 2018). At this time, all HEIs were owned by the state, and all levels of education were subsidized by the state to reach ideal equality for all citizens. Since the country got independence, higher educational instructions start privatization. At the beginning of 2000-2005, there was an increasing trend and kind of massification of private higher education institutions (Shervashidze, 2005). At that, time the country did not have any experience in establishing and managing private institutions, as there were no regulations and/or procedures for founding new HEIs. Consequently, for the end of 2005, the number of universities reached 172 which was an absolute record for such a small country as Georgia with 172461 students enrolled in, with a large proportion still coming on public Schools - 137021 . Private universities mainly had part-time programs, with the major fields on Law, Humanities, and Medicine. A relatively small proportion of students was coming to private institutions that's because there were not enough infrastructure and academic resources. As an entrance exam, the programs had basic requirements for enrolment, low quality of teaching, and therefore basic outcomes after graduation. Studying at the university ware considered as the way of obtaining an HE Diploma, which becomes a reason to increase numbers of unemployed young's (Fig. 2).

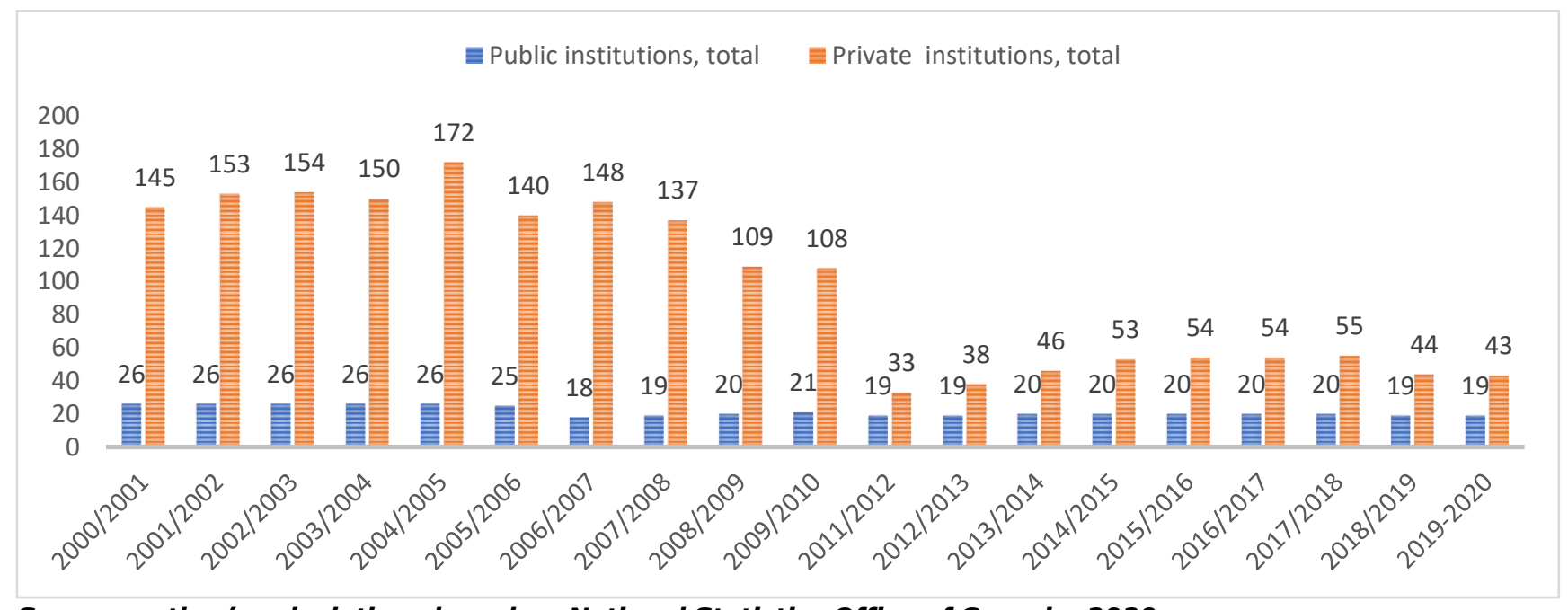

Source: author's calculations based on National Statistics Office of Georgia, 2020

Fig. 2. Number of State and Private Higher Educational Institutions 2000-2020

Another important feature was corruption in the higher education system. There are several studies, which offer reviews and cases of particular bribes at leading higher educational institutions (Heyneman, 2004; 2008; Karosanidze \& Christensen, 2005). As a result, it affected access to education, equity, and the quality of it. Uncertainties, corruption, easy access to education, create a sum of graduates with Higher education Diplomas and without certain skills.

In 2003 new government in Georgia started comprehensive reforms. The progressions that happened in the Higher education system were very important. The system ware completely patched up by entwined sets of changes. Most remarkably, they improve efficiency, eliminate corruption, and increase education quality assurance standards. 
In following years, particularly in 2011-2012 the number of Universities ware declined dramatically. The process was connected with the implementation of new regulations of HE and quality assurance standards. The number of universities accounted for only 52 both in the public and private sector with 95110 enrolled students. For the present moment, there are 19 state and 42 private higher educational establishments with 148803 registered students.

- Higher education policy planning problems; mismatching demand and supply at the national and regional level

The changing environment in the system of higher education and some major policy planning problems affect the demand and supply of the labour market. First of all, there is limited information on the relationship between higher education and the labour market conditions, although accreditation standards oblige educational institutions to create annual reports with employment statistics, data about the student or/and alumni employment are not collected on a systematic basis (Glonti, Lortkipanidze , \& Urushadze, 2017). Also, institutions have to adjust learning programs to the labour market demand, however, the indicators and verification sources are unclear. Neither, self-evaluation and external evaluation reports are comprehensive, consequently, do not exist objective evaluation reports.

According to the State Audit Office (2019), which contacts higher education programs and market compatibility efficiency audit, there are some major concerns:

1) Ministry of Education, Science, culture and sport of Georgia, annually subsidized some programs across the public institutions. Nonetheless, no suitable studies have been performed to determine priority directions or/and required professions in the labour market. Consequently, it has not been researched on how compatible are selected programs for the needs of the country.

2) There are cases when the priority studying programs are the fields that usually have high demand from the entrance students, while other fields of studies (such as: agronomy, agrarian technologies, architecture, food technology and etc.) have less attractiveness, but exactly those fields are considered as urgent for the country and demanded at the labour market. So, we receive a high supply in some professions and a deficit in another.

3) There is no research paper evaluating certain professions and needs for the labour market, which is caused by insufficient communication between responsible ministers and other stakeholders. As a result, we cannot analyse the compatibility between financed students and the real needs of the market. According to the Ministry of education, science, culture, and sport of Georgia, an absolute majority of graduates comes on the field of Social sciences, Business, and Law. The trend is similar in public and private universities on a national and regional basis. In other words, the labour market receives oversupply graduates from Social sciences, Business, and Law, whereas there is a qualified workers deficit in the fields of Engineering, manufacturing, and construction; agriculture sciences, etc. The policy problems concerns to both national and regional settings.

Analysing the unemployment rate by educational attainment shows that most unemployed population comes particularly from higher education. Fortunately, the trend is declining, and first, in the last 8 years, it is less than the unemployed population at intermediate non-vet education.

At the national level there is no statistics comparing unemployment trends based on qualification, specialization, and graduated university. 


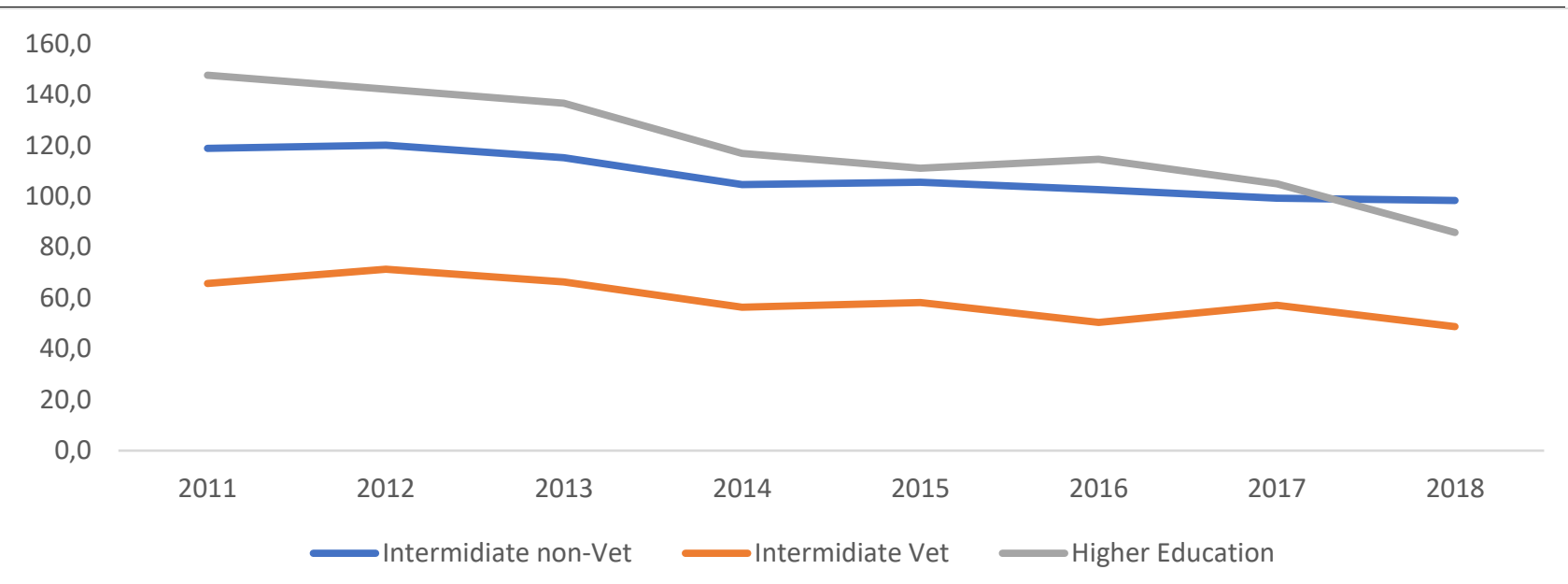

Source: author's calculations based on National Statistics Office of Georgia, 2018

Fig. 3. Unemployment rate by Education attainment

- Graduates Skills mismatch analyses

There is a lack of fruitful research literature in regards to graduates' skills mismatch in Georgia. A few studies argue as follows: According to the International Organization of Migration conduct a comprehensive study regarding unemployment and skilful unemployment (IOM, 2010). Research results show that even there is mass unemployment in the country, most employers have difficulties finding appropriate staff with relevant qualifications and experience.

One of the first representative surveys of enterprises was organized by the Ministry of Economy and Sustainable Development of Georgia (2017) researching the workforce, employment structure, assessments of vocational skills of employees employed by enterprises, and others. The research includes 19000 job vacancies in 5651 business organizations. Results show that almost half of the business organizations (45 \%) recruit new employees among friends, relatives, or/and other contacts. Also, they are looking for staff with the qualification of 3-5 years, so recent graduates face the problem of finding a relevant occupation. There was a significant lack of finding employees in the fields of science, service, office work, trade, art, STEM sciences, and others.

Unfortunately, there is not any direct measurement or research between skills demand and supply in Georgia. Only, education and occupation are considered campus-based skills (Badurashvili, 2019).

As employees raise the sounds, graduates' skills and abilities that individuals earn at campus-based are not sufficient for the labour market. Important indicators related to education-occupation mismatch analysis can be found at the Georgian Labour Market Demand Survey (Ministry of Labour, Health and Social Affairs of Georgia, 2015). The research sampling includes 63387 entities located at the capital and regional level, with over 908374 employed workers. Over 42 \% of companies reported that they usually need to employ foreign workers because there are no domestic workers with the required skills. Over $72 \%$ of companies also have difficulties in hiring applicants due to applicants' level of qualification and skills shortage. On the one hand, there are numbers of unemployed graduates and on the other hand, there is a specific professions deficit, like sheet metal workers, veterinarians, agronomists etc.

The authors conducted analysis of the yearly statistics of a private employment agency (HR.GE). The company is one of the leading organizations in posted vacancies and links labour market stakeholders and the unemployed population. The first five groups of posted vacancies come services and sales workers (31.5\%); technicians and associate professionals (22.2\%); professionals (15.4\%); clerical support workers (13.9\%); crafts and related trades workers (5.2\%). Major vacancies related to those five groups 
include the sales assistants, waiters, security guards, sales representatives, bartenders, domestic helpers etc. As a fact, the qualification requirement for the previously mentioned groups, in most cases is associated with vocational education rather than higher education.

- How regional-based HEIs can enhance the fresh graduates' employability and how does it help regional sustainability?

There is no preliminary research or correspondence between the educational institutions and the needs of labour market stakeholders in regards to graduates' qualifications and skills. Enterprises need to spend some amount of time and money to retrain graduates and prepare them for particular work. Due to that, enterprises mostly avoid recruiting fresh graduates. The educational mismatch is rather high among bachelor graduate women. Even if they get some particular positions, women are $10 \%$ less paid rather than men. Overall, graduates experience disappointment at the beginning of their careers.

As a result, major numbers of graduates are forced to take irrelevant jobs, comparing to their studying program, meaning that the skills and abilities that they develop during the educational process are limited to apply.

Research participants realizing that region-based HEIs have the huge role in the process of enhancement graduates' employability. To overcome the obstacle, institutions mention that they need financial resources from the state to increase academic staff, invite professionals from different fields, make the relevant public relations and start working in the parts of innovations. It will help them to empower graduates and create a soft and smooth transition from education to employment.

Unfortunate, today HEIs are passive receivers of political or economic changes in the country. We don't expect and they may not affect the overall unemployment tendency in the country but they can change future trends at regional bases. Well-planned educational process can decrease horizontal mismatch in the labour market and enhance regional sustainability by encouraging youth employment.

Based on in depth interviews and research results, we have defined several endorsements for improving the employment settings for recent graduates.

Initiate and implementing different learning courses. Students should have opportunities to develop self-employment and entrepreneur skills during their studying period.

- Strengthen the links with public and private enterprises, involve them in creating curriculums

- Set up and store annual records about graduates' employability and investigate horizontal mismatch problems.

- Create a supportive educational process for women and ensure their professional employability after graduation.

- Develop clear strategies and ensure higher education system compatibility with labour market requirements.

- Higher educational institutions should establish structural units for supporting the graduates' employability (such as: Technology transfer offices; start-up incubator etc.).

Regional sustainability can be enhanced by the following aspects:

- examine the regional challenges and enhance regional innovation to address the problems;

- encouraging enterprising, entrepreneurship, and economic growth;

- by developing new generations, promoting regional human capital;

- cooperation with regional authorities and linking universities with regional development. 


\section{Conclusions and recommendations}

The given paper aimed to analyse role of the region-based HEIs in regards of labour market formation at regional and national level. Study graduates' unemployment tendency, its causes and effects. Explore relationship between Georgian HEIs based in regions and SME's. Investigate the main challenges between these two sectors and define the optimization ways. The results were obtained from different sources, qualitative research with HEIs, exploring descriptive and analytical databases, as well as diverse national and international documents/reports. General results and recommendations are drawn bellow:

The tendency of unemployment in the country affects the graduates' employability possibilities in Georgia.

1) To a certain extent graduates' unemployment is encouraged by educational institutions, because they dramatically increase and recruit students in some particular fields (such es: Economics and Business, International Relations, Law, Humanities etc.) whereas a significant proportion of the workforce in that segment is self-employed (under the shadow economy) mismatched by occupation or/and unemployed. As a result, most of future graduates will be just additional oversupply on the labour market.

2) Majority of region based HEIs do not research labour require skills and qualifications yearly, institutions do not collect annual databases about graduates' employability, neither professional employability records.

3) Region based HEIs have very week connection with SMEs and they are partly involved in the educational/training process.

4) Higher educational institutions should establish structural units for supporting the graduates' employability.

5) With the intention of increasing the role of the HEIs' in regional sustainable development by forming qualitative labour force, universities should use all advantages that they have, create strong ties with SMEs, attract various stakeholders from different transdisciplinary, set and ensure continuous process of discourse.

6) In order to expand the findings and deepen research results, we recommend further research by combining qualitative and quantitative research in the future, involving not only HEIs and SMEs, but including the alumni and current students of HEIs.

\section{Bibliography}

1. Andrews, L., Higgins, A., Andrews, M., \& Lalor, J. (2012). Classic grounded theory to analyze secondary data: Reality and Reflections. The Grounded Theory Review 11 (1), 12-26.

2. Atkins, M. (1999). Oven-ready and self-basting: Taking stock of emoloyabability skills. Teaching in Higher Education 4(2), 2667-278.

3. Badurashvili, I. (2019). Skills Mismatch Measurement in Georgia. Georgia : European Training Foundation .

4. Bannett, N., Dunne, E., \& Carre, C. (2002). Developing skills in higher education and employment. ESRC Learning Society Programme.

5. Barnett, R. (2000). Realizing the University in an age of supercomplexity. Buckingham : SRHE \& Open University Press .

6. Beduwe, C., \& Giret, J. (2010). Mismatch of vocational graduates: What penalty on French labour market? Journal of Vocational Behavior, 78 (1), 68-79.

7. Bender , K., \& Roche, K. (2013). Educational mismatch and seld-employment. Economics of education Review, 65-95.

8. Bhattacherjee, A. (2012). Social Science Research: Principles, Methods and practices. Textbooks Collection 3. Retrieved 3 20, 2020, from https://scholarcommons.usf.edu/oa_textbooks/3/ 
9. Boudarbat, L., \& Chernoff, V. (2012). Education-job match among recent Canadian univrsity graduates. Applied Economics Letters 19, 1923-1926.

10. Carnevale , A., \& Cheah, B. (2013). Hard times 2013: College Majors, Unemployment, and Earnings. Reports by CEW.

11. Carnevale, A., Cheah, B., \& Strohl, J. (2013-07). Hard times: College majors, unemployment and earnings: Not all college degrees are created equal. Reports by CEW.

12. Chakhaia, L., \& Bregvadze, T. (2018). Georgia: Higher Education System Dynamics and Institutional Diversity. 25 Years of Transformations of Higher Education Systems in Post-Soviet Countries, 175-197.

13. Cosser, M. (2010). The skills cline: higher education and the supply-demand complex in South Africa. HIgher Education , 59:43-53.

14. Crebert, G., Bates, M., Bell, B., Patrick, C., \& Cragnolini, V. (2004, ). Developing generic skills at university, during work placement and in employment: graduates' perceptions. Higher Education Research \& Development; 23(2), 147-165.

15. Glonti, L., Lortkipanidze , T., \& Urushadze, N. (2017). Overview of the Higher Education System of Georgia. Tbilisi: Georgia National erasmus+ Office. Retrieved 01 20, 2021, from https://eacea.ec.europa.eu/sites/eacea-site/files/countryfiche_georgia_2017.pdf

16. Heyneman , S. (2004). Education and Corruption. International Journal of Educational, 637-648.

17. Heyneman, S. (2008). Three universities in Georgia, Kazakhstan and Kyrgyzstan: The struggle against corruption and for social cohesion. UNESCO PROSPECTS, 305-318.

18. Hwang, Y. (2017 Vol.3 (2)). What Is the Cause of Graduates' Unemployment? Focus on Individual Concerns and Perspectives. Journal of Educational Issues.

19. Johnston, M. P. (2014). Secondary Data Analysis: A Method of which the Time Has Come. Qualitative and Quantitative Methods in Libraries, 619-626. Retrieved 3 23, 2020, from http://qqml.net/papers/September_2014_Issue/336QQML_Journal_2014_Johnston_Sept_619-626.pdf

20. Karosanidze, T., \& Christensen, c. (2005). A new beginning for Georgia“s University Admissions. In Stealing the future. Corruption in the classroom. Ten real life experiences. Transparency Interntional.

21. Ministry of Economy and Sustainable Development of Georgia . (2017). Survey of business demand on skills. Ministry of Economy and Sustainable Development of Georgia . Retrieved 01 20, 2021, from http://www.Imis.gov.ge/Lmis/Lmis.Portal.Web/Handlers/GetFile.ashx?Type=Content\&ID=d2c29a21-366d40ae-9556-4594bdbfddbb

22. Ministry of Economy and Sustainable Development of Georgia. (2019). Labour Market Analysis of Georgia. Tbilisi. Retrieved 04 12, 2020, from http://www.Imis.gov.ge/Lmis/Lmis.Portal.Web/Handlers/GetFile.ashx?Type=Content\&ID=36da94d0-62684a8a-87fe-9fab0e86245b

23. Ministry of Education, Science, Culture and Sport of Georgia. (2020, 03 30). Authorized Institutions. Retrieved from https://www.mes.gov.ge/content.php?id=1855\&lang=eng

24. Ministry of Labour, Health and Social Affairs of Georgia. (2015). The Survey Report of Labour Market Demand Component. Tbilisi. Retrieved 04 12, 2020, from https://www.moh.gov.ge/uploads/files/oldMoh/01_GEO/Shroma/kvleva/4.pdf

25. Morley, L. (2001). Producing New Workers: quality, equality and employability in higher education. Quality in Higher Education , 7 (2), 131-138.

26. National Center for Educational Quality Enhancement . (2020, August 10). Retrieved from https://eqe.ge/eng/static/55/mission-and-vision

27. National Statistics Office of Georgia. (2020). HIgher Education Institutions and students enrolment. Retrieved 03 22, 2020, from https://www.geostat.ge/en

28. Nordin, M., Persson, I., \& Rooth, D. (2010). Education-occupation mismatch: Is there an income penalty? Economics od Educaiton review, 1047-1059.

29. Robst, J. (2006). Education and job match: The relatedness of college major and work. Economics of Education Review.

30. Robst, J. (2007). Education, College Major, and Job Match: Gender Differences in Reasons for Mismatch. Education Economics, 159-175.

31. Rudakov, V., Figueiredo, H., Teixeira , P., \& Roshchin, S. (2019). The Impact of Horizontal Job-Education Mismatches on the Earnings of Recent University Graduates in Russia. Bonn, Germany: IZA institute of Labor Economics .

32. Shervashidze, G. (2005). Private Higher Education in Georgia. Main Tendencies. Paris: UNESCO.

33. State Audit Office. (2019). State Audit Report. Tbilisi: State Audit Office.

34. Tsiklashvili, N., \& Turmanidze, T. (2018). Quantitative and qualitative indicators of gender eqyality. Paper presented at III international scientific and practical forum "Innovations in science "the challenges of our time", Bulgaria- Ukraine.

35. UNESCO. (2005). UN Decade of ESD. Retrieved from https://en.unesco.org/themes/education-sustainabledevelopment/what-is-esd/un-decade-of-esd

36. USAID and IOM (US Agency for International Development and International Organisation for Migration). (2010). Labour market in Georgia. https://georgia.iom.int/. 